\title{
Off-pump versus on-pump coronary artery bypass grafting in patients with left ventricular dysfunction
}

\author{
Chikara Ueki, MD, ${ }^{\mathrm{a}, \mathrm{b}}$ Hiroaki Miyata, $\mathrm{PhD},{ }^{\mathrm{b}}$ Noboru Motomura, MD, PhD, ${ }^{\mathrm{b}}$ \\ Genichi Sakaguchi, MD, PhD, ${ }^{\mathrm{a}, \mathrm{b}}$ Takehide Akimoto, MD, PhD, ${ }^{\mathrm{a}, \mathrm{b}}$ and Shinichi Takamoto, MD, $\mathrm{PhD}^{\mathrm{b}}$
}

\section{ABSTRACT}

Objective: Using data from the Japan Adult Cardiovascular Surgery Database, we evaluated the prognostic influence of off-pump technique in patients with low ejection fraction who underwent coronary artery bypass grafting.

Methods: We analyzed 2187 patients with an ejection fraction $<0.30$ who underwent primary, nonemergency, isolated coronary artery bypass grafting between 2008 and 2012, as reported in the Japan Adult Cardiovascular Surgery Database. Patients were divided into on-pump $(\mathrm{n}=1134 ; 51.1 \%)$ and off-pump $(\mathrm{n}=1053$; $48.9 \%$ ) coronary artery bypass grafting groups. Propensity-score matching for 20 preoperative variables was performed, and early mortality and morbidity were compared between matched groups.

Results: Propensity-score matching created 918 pairs. Of the 918 patients in the off-pump group, conversion to an on-pump procedure occurred in $56(6.1 \%)$. Compared with on-pump, off-pump technique was associated with significantly lower incidences of 30 -day death $(1.7 \%$ vs $3.7 \% ; P=.01)$, operative death $(3.3 \%$ vs $6.1 \% ; P=.006)$, mediastinitis $(1.9 \%$ vs $3.4 \% ; P=.041)$, reoperation for bleeding $(0.9 \%$ vs $3.5 \% ; P<.001)$, and prolonged ventilation $(8.2 \%$ vs $13.4 \% ; P<.001)$. Comparison of patients undergoing off-pump versus on-pump procedures demonstrated no significant differences in the incidence of stroke $(1.5 \%$ vs $2.1 \% ; P=.38)$, renal failure $(6.1 \%$ vs $7.4 \% ; P=.26)$, and postoperative dialysis $(3.1 \%$ vs $4.4 \% ; P=.14)$. Institutional volume-adjusted analysis confirmed most of these results.

Conclusions: Off-pump coronary artery bypass grafting is associated with significantly reduced early mortality and morbidity in patients with an ejection fraction $<0.30$. (J Thorac Cardiovasc Surg 2016;151:1092-8)

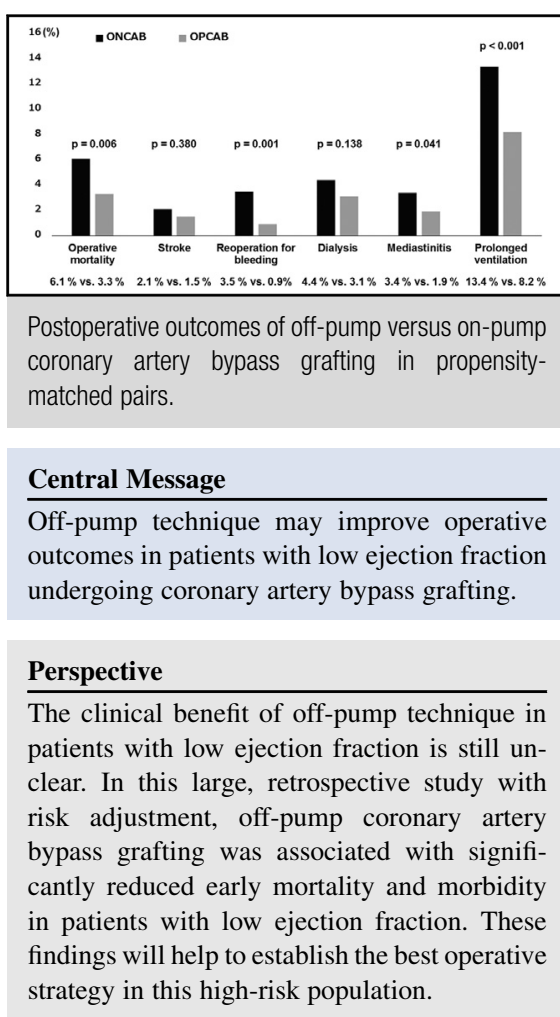

See Editorial Commentary page 1099.
Although the clinical benefits of off-pump coronary artery bypass (OPCAB) have not been demonstrated in large randomized trials, ${ }^{1,2}$ multiple observational studies have shown the mortality and/or morbidity benefit of OPCAB versus on-pump coronary artery bypass $(\mathrm{ONCAB})$, especially in high-risk subgroups. ${ }^{3-6}$ In

From the ${ }^{\mathrm{a} D e p a r t m e n t}$ of Cardiovascular Surgery, Shizuoka General Hospital, Shizuoka, Japan; and Japan Cardiovascular Surgery Database Organization, Tokyo, Japan.

Read at the 95th Annual Meeting of The American Association for Thoracic Surgery, Seattle, Washington, April 25-29, 2015.

Received for publication April 23, 2015; revisions received Oct 23, 2015; accepted for publication Nov 15, 2015; available ahead of print Dec 23, 2015.

Address for reprints: Chikara Ueki, MD, Department of Cardiovascular Surgery, Shizuoka General Hospital, 4-27-1 Kita-Ando Aoi-ku, Shizuoka 420-8527, Japan (E-mail: uekichikara@gmail.com).

0022-5223/\$36.00

Copyright (c) 2016 by The American Association for Thoracic Surgery

http://dx.doi.org/10.1016/j.jtcvs.2015.11.023 addition to other representative risk factors, including advanced age, diabetes, and renal dysfunction, left ventricular dysfunction has been shown to be a predictor of early mortality after coronary artery bypass grafting (CABG).

Recent large randomized trials-the Randomized On/Off Bypass (ROOBY) trial and the CABG Off or On Pump Revascularization Study (CORONARY) —included only a small number of patients with low ejection fraction (EF). ${ }^{1,2}$ Hence, these randomized trials could not evaluate the prognostic benefit of OPCAB in patients with low EF. Moreover, most retrospective studies from single centers also have significant limitations such as a relatively low sample size and a strong bias in treatment choice. Considering this situation, a risk-adjusted retrospective study of a large database, such as the Society of Thoracic Surgeons (STS) national database, plays an important role in establishing the best strategy for patients with low EF undergoing CABG. ${ }^{8}$ 


\begin{tabular}{|c|c|}
\hline \multicolumn{2}{|c|}{ Abbreviations and Acronyms } \\
\hline CABG & $=$ coronary artery bypass grafting \\
\hline CORONC & $=\mathrm{CABG}$ Off or On Pump \\
\hline & Revascularization Study \\
\hline $\mathrm{EF}$ & $=$ ejection fraction \\
\hline ICU & $=$ intensive care unit \\
\hline JACVSD & $\begin{aligned}= & \text { Japan Adult Cardiovascular } \\
& \text { Surgery Database }\end{aligned}$ \\
\hline MACE & $\begin{aligned}= & \text { major adverse cardiovascular } \\
& \text { events }\end{aligned}$ \\
\hline NCD & $=$ National Clinical Database \\
\hline ONCAB & $=$ on-pump coronary artery bypass \\
\hline OPCAB & $=$ off-pump coronary artery bypass \\
\hline ROOBY & $=$ Randomized On/Off Bypass trial \\
\hline STS & $=$ Society of Thoracic Surgeons \\
\hline
\end{tabular}

The purpose of this study was to evaluate the prognostic influence of OPCAB in patients with an $\mathrm{EF}<0.30$ using a large sample from the Japan Adult Cardiovascular Surgery Database (JACVSD).

\section{PATIENTS AND METHODS}

The institutional review board of our institution approved this study. Informed consent was obtained from each patient to allow his or her data to be entered into the database.

\section{The JACVSD}

JACVSD, which was created to enable evaluation of surgical outcomes after cardiovascular procedures in hospitals throughout Japan, currently captures clinical information from most Japanese hospitals.

The 255 variables in the data collection form are nearly identical to those of the STS national database. The content of the JACVSD (http://www. jacvsd.umin.jp) and STS databases (http://sts.org) can be viewed online. The JACVSD has developed software for web-based data collection that allows data managers at participating hospitals to submit data electronically to the central office. Participation in JACVSD is voluntary, but there is a high degree of completeness of the data. In addition, the accuracy of submitted data is maintained by regular data auditing in which monthly visits are made to participating hospitals to check the reported data against clinical records. Data validity is further confirmed by independent comparison of specific hospitals' volume of cardiac surgeries entered in JACVSD with that reported in the annual survey of the Japanese Association for Thoracic Surgery. Further, in 2010 and later, the JACVSD served as a part of the National Clinical Database (NCD) in Japan, which includes clinician-initiated databases reflecting all surgical. The NCD covers $95 \%$ of total surgical procedures.

\section{Study Population}

We examined the data for patients included in the JACVSD from January 1, 2008, to December 31, 2012. Records with missing age (or out of range), sex, or 30-day status (see Study End Points for an explanation) were excluded. With the exception of body surface area, and preoperative creatinine value, all missing or out-of-range values were imputed using the variable-specific median value. After this data cleaning, patients with an $\mathrm{EF}<0.30$ who underwent isolated CABG were included. In the JACVSD, echocardiography, left ventriculography, radionucleotide scan, physician estimation, and other methods (including magnetic resonance imaging) were permitted for the evaluation of EF. The distribution of determination was equivalent between the 2 groups $(P=.089)$ and for most of patients was evaluated by echocardiography $(62.6 \%)$ and left ventriculography gram $(21.5 \%)$. Missing evaluation method occurred in $14.3 \%$ of all patients, and radionucleotide scan $(1.0 \%)$, physician estimation $(0.4 \%)$, and other methods $(0.1 \%)$ were used in only a small portion of patients. Exclusion criteria were emergency or salvage status and redo surgery. Thus, 2187 consecutive patients were included in the analysis. Because intention-to-treat principle was applied to all statistical analyses, patients were divided into those intended for ON$\mathrm{CAB}(\mathrm{n}=1134 ; 51.1 \%)$ and $\mathrm{OPCAB}(\mathrm{n}=1053 ; 48.9 \%)$ procedure. $\mathrm{Pa}-$ tients intended for OPCAB were included in the OPCAB group even if they were converted intraoperatively to ONCAB.

\section{Study End Points}

The study end points were 30-day mortality, operative mortality, and postoperative morbidity. Thirty-day mortality was defined as death within 30 days after surgery. Operative mortality was defined as death occurring within 30 days after surgery and death during the index hospitalization. Major adverse cardiovascular events (MACEs) were defined as a combined end point that included operative mortality, perioperative myocardial infarction, and stroke. Renal failure was defined as an increase in serum creatinine concentration to twice preoperative levels or to $>2.0 \mathrm{mg} / \mathrm{dL}$, or new requirement for dialysis or hemofiltration. Perioperative myocardial infarction was defined as at least 2 of the following: continuous angina for $>20$ minutes regardless of nitrite treatment or rest, elevation of cardiac enzyme levels (creatine kinase-myocardial band) $>1 / 20$ of the total creatine kinase level or double the preoperative level and/or lactate dehydrogenase isozyme subtype $1>$ subtype 2 and/or positive troponin-I and/or troponin-T), new cardiac wall-motion abnormalities, and Q waves or ST-segment elevation/T-wave changes in $>2$ serial 12-lead electrocardiograms.

\section{Propensity Matching and Statistical Analysis}

Propensity-score matching was used to adjust differences in baseline characteristics because patients were not randomly assigned to receive ONCAB or OPCAB. Each patient's estimated propensity score, which is the likelihood of the patient being intended to undergo OPCAB, was calculated using a multivariate logistic model that included 20 preoperative variables: age, presence of unstable angina, extracardiac vascular disease, cerebrovascular disease (ie, presence of stroke or a history of transient ischemic attack), hypertension, hyperlipidemia, diabetes, preoperative hemodialysis, chronic lung disease (mild, moderate, or severe), arrhythmia, aortic stenosis greater than grade 1 , aortic regurgitation greater than grade 2 , mitral regurgitation greater than grade 2 , tricuspid regurgitation greater than grade 2, cardiogenic shock, history of myocardial infarction, congestive heart failure, New York Heart Association functional class III or IV, triple-vessel disease, and left main disease. The HosmerLemeshow test result was not significant $(P=.292)$ and the c-statistic for this propensity model was $0.599(0.576-0.623 ; 95 \%$ confidence interval). We then performed a 1-to-1 matched analysis on the basis of the estimated propensity score of each patient. The propensity scores were compared between $\mathrm{ONCAB}$ and $\mathrm{OPCAB}$ patients, with a match occurring when 1 patient in the ONCAB group had an estimated score within 0.6 standard deviations of a patient in the OPCAB group. If 2 or more patients in the ONCAB group met this criterion, we randomly selected 1 patient for matching. We also performed univariate comparisons of patient characteristics and outcome variables between the propensity-score-matched groups of ONCAB and OPCAB patients using Fisher exact test and Student $t$ test as appropriate. In addition, an institutional-volume adjusted analysis was performed by using a mixed-effects logistic regression model. In this model, the annual isolated CABG case volumes of hospitals were included as a covariate. 
TABLE 1. Patient characteristics of the original and matched cohorts

\begin{tabular}{|c|c|c|c|c|c|c|}
\hline \multirow[b]{2}{*}{ Variable } & \multicolumn{3}{|c|}{ Original cohort } & \multicolumn{3}{|c|}{ Matched cohort } \\
\hline & $\begin{array}{c}\text { ONCAB } \\
(\mathbf{n}=\mathbf{1 1 3 4}) \\
\end{array}$ & $\begin{array}{c}\text { OPCAB } \\
(\mathbf{n}=\mathbf{1 0 5 3})\end{array}$ & $\begin{array}{c}P \\
\text { value }\end{array}$ & $\begin{array}{c}\text { ONCAB } \\
(\mathrm{n}=918) \\
\end{array}$ & $\begin{array}{c}\text { OPCAB } \\
(\mathbf{n}=918) \\
\end{array}$ & $\begin{array}{c}P \\
\text { value }\end{array}$ \\
\hline Ejection fraction $(\%)$ & $26.6 \pm 10.4$ & $27.2 \pm 7.9$ & .159 & $26.8 \pm 11.1$ & $27.0 \pm 7.8$ & .734 \\
\hline Age (yrs) & $65.7 \pm 10.2$ & $67.4 \pm 10.1$ & .002 & $66.7 \pm 9.8$ & $66.2 \pm 10.0$ & .281 \\
\hline Male sex & $978(86.2)$ & $903(85.8)$ & .742 & $784(85.4)$ & $786(85.6)$ & .895 \\
\hline Body mass index & $23.0 \pm 3.7$ & $22.9 \pm 3.8$ & .417 & $22.9 \pm 3.7$ & $23.0 \pm 3.8$ & .557 \\
\hline Smoking history & $742(65.4)$ & $701(66.6)$ & .574 & $592(64.5)$ & $610(66.4)$ & .377 \\
\hline Diabetes & $731(64.5)$ & $633(60.1)$ & .036 & $574(62.5)$ & $581(63.3)$ & .735 \\
\hline Hyperlipidemia & $669(59.0)$ & $571(54.2)$ & .025 & $517(56.3)$ & $520(56.6)$ & .888 \\
\hline Hypertension & 835 (73.6) & $758(72.0)$ & .387 & $668(72.8)$ & $669(72.9)$ & .958 \\
\hline Serum creatinine $(\mathrm{mg} / \mathrm{dL})$ & $2.19 \pm 3.42$ & $1.96 \pm 2.47$ & .072 & $2.13 \pm 3.54$ & $2.01 \pm 2.53$ & .403 \\
\hline Preoperative eGFR $\left(\mathrm{mL} / \mathrm{min} / 1.73 \mathrm{~m}^{2}\right)$ & $39.0 \pm 21.0$ & $39.9 \pm 21.5$ & .333 & $39.3 \pm 20.6$ & $40.1 \pm 22.0$ & .381 \\
\hline Preoperative dialysis & $160(14.1)$ & $128(12.2)$ & .177 & $117(12.7)$ & $120(13.1)$ & .835 \\
\hline Cerebrovascular disease & $150(13.2)$ & $182(17.3)$ & .008 & $133(14.5)$ & $131(14.3)$ & .894 \\
\hline Carotid stenosis & $73(6.4)$ & $94(8.9)$ & .028 & $61(6.6)$ & $78(8.5)$ & .134 \\
\hline Chronic lung disease & $120(10.6)$ & $148(14.1)$ & .013 & $105(11.4)$ & $95(10.3)$ & .454 \\
\hline Extracardiac vascular disease & $212(18.7)$ & $223(21.2)$ & .146 & $176(19.2)$ & $174(19.0)$ & .905 \\
\hline Prior percutaneous coronary intervention & $279(24.6)$ & $263(25.0)$ & .840 & $229(24.9)$ & $225(24.5)$ & .829 \\
\hline Prior myocardial infarction & $693(61.1)$ & $615(58.4)$ & .197 & $543(59.2)$ & $547(59.6)$ & .849 \\
\hline Congestive heart failure & $511(45.1)$ & $426(40.5)$ & .030 & $385(41.9)$ & $386(42.0)$ & .962 \\
\hline Unstable angina & $355(31.3)$ & $321(30.5)$ & .678 & $282(30.7)$ & $285(31.0)$ & .880 \\
\hline Preoperative shock & $74(6.5)$ & $58(5.5)$ & .318 & $55(6.0)$ & $54(5.9)$ & .921 \\
\hline Preoperative arrhythmia & $155(13.7)$ & $127(12.1)$ & .262 & $115(12.5)$ & $115(12.5)$ & 1.000 \\
\hline $\begin{array}{l}\text { New York Heart Association functional } \\
\text { class III or IV }\end{array}$ & $506(44.6)$ & $392(37.2)$ & $<.001$ & $370(40.3)$ & $377(41.1)$ & .739 \\
\hline Left main disease $\geq 50 \%$ & $405(35.7)$ & $355(33.7)$ & .326 & $320(34.9)$ & $326(35.5)$ & .769 \\
\hline Triple-vessel disease & $955(84.2)$ & $840(79.8)$ & .007 & $757(82.5)$ & $764(83.2)$ & .665 \\
\hline Aortic stenosis $\geq$ grade 1 & $20(1.8)$ & $32(3.0)$ & .05 & $15(1.6)$ & $11(1.2)$ & .429 \\
\hline Mitral stenosis $\geq$ grade 1 & $13(1.1)$ & $10(0.9)$ & .652 & $11(1.2)$ & $6(0.7)$ & .223 \\
\hline Aortic insufficiency $\geq$ grade 2 & $87(7.7)$ & $108(10.3)$ & .034 & $77(8.4)$ & $71(7.7)$ & .607 \\
\hline Mitral insufficiency $\geq$ grade 2 & $326(28.7)$ & $361(34.3)$ & .005 & $275(30.0)$ & $272(29.6)$ & .878 \\
\hline Tricuspid insufficiency $\geq$ grade 2 & $131(11.6)$ & $144(13.7)$ & .135 & $113(12.3)$ & $107(11.7)$ & .666 \\
\hline Urgent status & $191(16.8)$ & $165(15.7)$ & .458 & $154(16.8)$ & $148(16.1)$ & .706 \\
\hline
\end{tabular}

Data are presented as $\mathrm{n}(\%)$ or mean \pm standard deviation. $O N C A B$, On-pump coronary artery bypass; $O P C A B$, off-pump coronary artery bypass; $e G F R$, estimated glomerular filtration rate.

\section{RESULTS}

\section{Patient Characteristics of All Unmatched Patients}

Patient characteristics of the entire unmatched cohort are presented in Table 1. The OPCAB group was significantly older and had significantly higher prevalence of cerebrovascular disease, carotid stenosis, respiratory disease, aortic valve insufficiency, and mitral valve insufficiency. However, the ONCAB group had significantly higher prevalence of diabetes mellitus, hyperlipidemia, congestive heart failure, New York Heart Association functional class III or IV, and triple-vessel disease.

\section{Operative Data and Clinical Outcome for the Original, Unmatched Cohort}

Table 2 shows operative data for the entire unmatched cohort. The OPCAB group had significantly fewer distal anastomoses but employed both the right and left internal thoracic arteries significantly more frequently. Unplanned conversion from $\mathrm{OPCAB}$ to $\mathrm{ONCAB}$ occurred in 64 patients $(6.1 \%)$. Aortic crossclamping was performed in 406 patients $(35.8 \%)$ in the ONCAB group. In $72.2 \%$ of the $\mathrm{OPCAB}$ group, proximal anastomosis was performed without aortic clamping (326 patients [31.0\%] with aortic no-touch technique and 434 patients [41.2\%] with a suture device). Operative durations were significantly shorter in the OPCAB group (316.0 vs 376.3 minutes; $P<.001$ ).

Several early outcomes were significantly better in the OPCAB group (Table 3), which had significantly lower 30-day mortality and operative mortality and significantly lower incidence of reoperation for bleeding, deep sternal wound infection, prolonged ( $>24$ hours) mechanical ventilation, prolonged ( $\geq 8$ days) intensive care unit (ICU) stay, and perioperative transfusion. Although the incidence of MACEs was significantly lower in the OPCAB group, the 
TABLE 2. Operative data for the original cohort

\begin{tabular}{lccc}
\hline \multicolumn{1}{c}{ Variable } & $\begin{array}{c}\text { ONCAB } \\
(\mathbf{n = 1 1 3 4})\end{array}$ & $\begin{array}{c}\text { OPCAB } \\
(\mathbf{n}=\mathbf{1 0 5 3})\end{array}$ & $\begin{array}{c}\boldsymbol{P} \\
\text { value }\end{array}$ \\
\hline Operative duration (min) & $376.3 \pm 105.5$ & $316.0 \pm 101.3$ & $<.001$ \\
CPB time (min) & $153.5 \pm 59.1$ & - & - \\
Distal anastomoses & $3.35 \pm 1.05$ & $3.15 \pm 1.27$ & $<.001$ \\
Proximal anastomosis & & & \\
$\quad$ Aortic no-touch & $114(10.1)$ & $326(31)$ & $<.001$ \\
$\quad$ Partial clamp & $327(28.8)$ & $269(25.5)$ & .084 \\
$\quad$ Suture device & $286(25.2)$ & $434(41.2)$ & $<.001$ \\
$\quad$ Total clamp & $406(35.8)$ & $24(2.3)$ & $<.001$ \\
ITA use & & & \\
$\quad$ Left & $1031(90.9)$ & $978(92.9)$ & .094 \\
$\quad$ Right & $264(23.3)$ & $404(38.4)$ & $<.001$ \\
$\quad$ Bilateral & $245(21.6)$ & $383(36.4)$ & $<.001$ \\
None & $87(7.7)$ & $57(5.4)$ & .033 \\
\hline
\end{tabular}

Data are presented as mean \pm standard deviation or $\mathrm{n}(\%)$. ONCAB, On-pump coronary artery bypass; $O P C A B$, off-pump coronary artery bypass; $C P B$, cardiopulmonary bypass; ITA, internal thoracic artery.

incidence of stroke, perioperative myocardial infarction, renal failure, and renal failure requiring dialysis did not differ between groups.

\section{Outcomes of Propensity Score-Matched Patients}

Baseline characteristics of the matched cohort are shown in Table 1. There were no significant differences in any preoperative factor between the 2 groups.

Table 4 shows operative data for the matched cohort, in which the OPCAB group had slightly fewer distal anastomoses but received bilateral internal thoracic artery grafting significantly more frequently. Aortic crossclamping was performed in 325 patients $(35.4 \%)$ in the ONCAB group. In $71.8 \%$ of the OPCAB group, proximal anastomosis

TABLE 3. Postoperative outcomes in the original cohort

\begin{tabular}{lccr}
\hline \multicolumn{1}{c}{ Outcome } & $\begin{array}{c}\text { ONCAB } \\
(\mathbf{n}=\mathbf{1 1 3 4})\end{array}$ & $\begin{array}{c}\text { OPCAB } \\
(\mathbf{n}=\mathbf{1 0 5 3})\end{array}$ & $\begin{array}{c}\boldsymbol{P} \\
\text { value }\end{array}$ \\
\hline 30-d Mortality & $42(3.7)$ & $20(1.9)$ & .011 \\
Operative mortality & $67(5.9)$ & $36(3.4)$ & .006 \\
Perioperative myocardial infarction & $7(0.6)$ & $6(0.6)$ & .885 \\
Stroke & $23(2.0)$ & $20(1.9)$ & .828 \\
Major adverse cardiovascular events* & $90(7.9)$ & $54(5.1)$ & .008 \\
Reoperation for bleeding & $38(3.4)$ & $8(0.8)$ & $<.001$ \\
Renal failure & $81(7.1)$ & $61(5.8)$ & .201 \\
Dialysis & $49(4.3)$ & $30(2.8)$ & .065 \\
Mediastinitis & $39(3.4)$ & $20(1.9)$ & .026 \\
Septicemia & $25(2.2)$ & $17(1.6)$ & .315 \\
Atrial fibrillation & $143(12.6)$ & $135(12.8)$ & .883 \\
Perioperative transfusion & $898(79.2)$ & $667(63.3)$ & $<.001$ \\
Prolonged ventilation $\dagger$ & $153(13.5)$ & $84(8.0)$ & $<.001$ \\
ICU stay $\geq 8 \mathrm{~d}$ & $200(17.6)$ & $125(11.9)$ & $<.001$ \\
Readmission within 30 d & $28(2.5)$ & $28(2.7)$ & .779 \\
\hline D. & &
\end{tabular}

Data are presented as n (\%). ONCAB, On-pump coronary artery bypass; OPCAB, off-pump coronary artery bypass; ICU, intensive care unit. *Includes operative mortality, myocardial infarction, and stroke. $\nmid$ Defined as $\geq 24$ hours.
TABLE 4. Operative data in propensity-matched pairs

\begin{tabular}{|c|c|c|c|}
\hline Variable & $\begin{array}{c}\text { ONCAB } \\
(n=918)\end{array}$ & $\begin{array}{c}\text { OPCAB } \\
(n=918)\end{array}$ & $\begin{array}{c}P \\
\text { value }\end{array}$ \\
\hline Operative duration (min) & $375.4 \pm 103.8$ & $322.5 \pm 101.8$ & $<.001$ \\
\hline CPB time (min) & $152.1 \pm 59.2$ & - & - \\
\hline Distal anastomoses & $3.34 \pm 1.05$ & $3.21 \pm 1.26$ & .019 \\
\hline \multicolumn{4}{|l|}{ Proximal anastomosis } \\
\hline Aortic no-touch & 97 (10.6) & $278(30.3)$ & $<.001$ \\
\hline Partial clamp & $268(29.2)$ & 235 (25.6) & .084 \\
\hline Suture device & $228(24.8)$ & $381(41.5)$ & $<.001$ \\
\hline Total clamp & 325 (35.4) & $24(2.6)$ & $<.001$ \\
\hline \multicolumn{4}{|l|}{ ITA use } \\
\hline Left & $826(90.0)$ & $856(93.2)$ & .012 \\
\hline Right & $208(22.7)$ & $366(39.9)$ & $<.001$ \\
\hline Bilateral & $193(21.0)$ & 348 (37.9) & $<.001$ \\
\hline None & $80(8.7)$ & $47(5.1)$ & .002 \\
\hline
\end{tabular}

Data are presented as $\mathrm{n}(\%)$ or mean \pm standard deviation. $O N C A B$, On-pump coronary artery bypass; $O P C A B$, off-pump coronary artery bypass; $C P B$, cardiopulmonary bypass; ITA, internal thoracic artery.

was performed without aortic clamping (278 patients [30.3\%] with aortic no-touch technique and 381 patients [41.5\%] with a suture device). After matching, operative durations were still significantly shorter in the OPCAB group. Unplanned conversion from $\mathrm{OPCAB}$ to $\mathrm{ONCAB}$ occurred in 56 patients $(6.1 \%)$, among whom operative mortality was $12.5 \%$ (7 patients). Of these patients with unplanned conversion, $40(71.4 \%)$ were converted to ONCAB because of hemodynamic instability.

After propensity-score matching, several clinical outcomes were still better in the OPCAB group, which had significantly lower 30-day mortality and operative mortality as well as significantly lower incidences of reoperation for bleeding, deep sternal wound infection, prolonged ventilation, prolonged ICU stay, and perioperative transfusion (Table 5). Although the incidence of MACE was lower in the OPCAB group $(P=.008)$, the incidence of stroke, perioperative myocardial infarction, renal failure, and renal failure requiring dialysis did not differ between groups. Institutional volume-adjusted analysis confirmed most of the results of primary analysis (Table 6).

\section{DISCUSSION}

The benefit of OPCAB technique in patients with a low $\mathrm{EF}$ is still unclear. The recent large randomized controlled trials (the ROOBY and CORONARY trials) did not show improved mortality in the OPCAB groups. ${ }^{1,2}$ However, in both studies, patients with an $\mathrm{EF}<0.35$ comprised only a small portion of the entire cohort. In the ROOBY trial patients with a low EF accounted for only $5.7 \%$ of the entire cohort, ${ }^{1}$ whereas in the CORONARY trial patients with a low EF accounted for only $5.4 \%$ of OPCAB group and $5.6 \%$ of $\mathrm{ONCAB}$ group. ${ }^{2}$ Therefore, these randomized controlled trials could not reach definite conclusions about the best strategy for surgical coronary revascularization in 
TABLE 5. Postoperative outcomes in propensity-matched pairs

\begin{tabular}{|c|c|c|c|}
\hline Outcome & $\begin{array}{c}\text { ONCAB } \\
(n=918) \\
\end{array}$ & $\begin{array}{c}\text { OPCAB } \\
(n=918) \\
\end{array}$ & $\begin{array}{c}P \\
\text { value } \\
\end{array}$ \\
\hline 30-d Mortality & $34(3.7)$ & $16(1.7)$ & .0 \\
\hline Operative mortality & $56(6.1)$ & $30(3.3)$ & \\
\hline Perioperative myocardial infarction & $7(0.8)$ & $6(0.7)$ & \\
\hline Stroke & $19(2.1)$ & $14(1.5)$ & \\
\hline Major adverse cardiovascular event* & $76(8.3)$ & $43(4.7)$ & \\
\hline Reoperation for bleeding & $32(3.5)$ & $8(0.9)$ & .0 \\
\hline Renal failure & $68(7.4)$ & $56(6.1)$ & \\
\hline Dialysis & $40(4.4)$ & $28(3.1)$ & .13 \\
\hline Mediastinitis & $31(3.4)$ & $17(1.9)$ & .0 \\
\hline Septicemia & $22(2.4)$ & $14(1.5)$ & .17 \\
\hline Atrial fibrillation & $119(13.0)$ & $114(12.4)$ & .7 \\
\hline Perioperative transfusion & $727(79.2)$ & $578(63.0)$ & $<.0$ \\
\hline Prolonged ventilation $\dagger$ & $123(13.4)$ & $75(8.2)$ & $<.00$ \\
\hline ICU stay $\geq 8 \mathrm{~d}$ & $159(17.3)$ & $111(12.1)$ & .00 \\
\hline Readmission within $30 \mathrm{~d}$ & $27(2.9)$ & $26(2.8)$ & 8 \\
\hline
\end{tabular}

Data are presented as n (\%). ONCAB, On-pump coronary artery bypass; $O P C A B$, off-pump coronary artery bypass; $I C U$, intensive care unit. *Includes operative mortality, myocardial infarction, and stroke. $\dagger$ Defined as $\geq 24$ hours.

low-EF patients. In this context, large retrospective studies using appropriate risk-adjustment methods are still required to establish a sound treatment strategy for patients with a low EF undergoing CABG.

The Japanese Association for Thoracic Surgery reported that intended $\mathrm{OPCAB}$ is performed in more than $60 \%$ of all patients undergoing CABG in Japan. ${ }^{9}$ As shown in our analysis, even among $\mathrm{CABG}$ patients with left ventricular dysfunction, intended OPCAB accounted for approximately half of this high-risk group. We found that in patients with low EF, OPCAB was associated with significant reductions in 30-day mortality and operative mortality, and with a significantly lower incidence of reoperation for bleeding, mediastinitis, perioperative transfusion, prolonged mechanical ventilation, and prolonged ICU stay. The largest retrospective study of OPCAB in patients with low EF was recently conducted using data from the STS national database and demonstrated the clinical benefit of OPCAB. ${ }^{8}$ The present study, which is from Japan, where OPCAB is performed more frequently than in other

TABLE 6. Institutional-volume adjusted odds ratios (ORs) of onpump coronary artery bypass versus off-pump coronary artery bypass

\begin{tabular}{lcc}
\hline \multicolumn{1}{c}{ Outcome } & OR $(\mathbf{9 5} \%$ confidence interval $)$ & $\boldsymbol{P}$ value \\
\hline 30-d Mortality & $0.447(0.238-0.839)$ & .012 \\
Operative mortality & $0.521(0.326-0.832)$ & .006 \\
Stroke & $0.723(0.355-1.475)$ & .373 \\
Reoperation for bleeding & $0.247(0.112-0.546)$ & .001 \\
Renal failure & $0.878(0.605-1.275)$ & .264 \\
Dialysis & $0.740(0.447-1.225)$ & .242 \\
Mediastinitis & $0.547(0.297-1.007)$ & .053 \\
Prolonged ventilation* & $0.582(0.427-0.793)$ & .001 \\
\hline
\end{tabular}

*Defined as $\geq 24$ hours. countries, is the second-largest retrospective study comparing $\mathrm{OPCAB}$ and $\mathrm{ONCAB}$ in patients with low EF.

First, OPCAB significantly reduced 30-day mortality $(1.7 \%$ in OPCAB vs $3.7 \%$ in ONCAB; odds ratio [OR], $0.48)$ and operative mortality (3.3\% in OPCAB vs $6.1 \%$ in ONCAB; OR, 0.52) in patients with low EF. This is consistent with the results of the meta-analysis of retrospective studies and the report from the STS national database. In their meta-analysis of 13 retrospective studies that included only patients with poor left ventricular function, Jarral and colleagues ${ }^{10}$ reported a $39 \%$ reduction in the risk of 30-day mortality in the OPCAB cohort (OR, 0.61). Based on propensity-score analysis using the STS national database, Keeling and colleagues ${ }^{8}$ reported that OPCAB was associated with significantly lower in-hospital mortality (adjusted OR, 0.82 in all centers and 0.63 in high-volume centers) in patients with an $\mathrm{EF}<0.30$. Other studies have suggested that the benefit of OPCAB may be more apparent in high-risk patients. Puskas and colleagues ${ }^{3}$ reported that there was a significant mortality benefit for OPCAB in patients with STS predicted risk of mortality $>0.025$ (OR, 0.45; 95\% confidence interval, 0.33-0.63). In addition, a report using data from the STS national database to compare outcomes of OPCAB and ONCAB showed that OPCAB was associated with a greater reduction in mortality and morbidity in patients with higher STS predicted risk of mortality scores. ${ }^{11}$ These results may explain the risk-reduction benefit of OPCAB in patients with low EF. Preoperative renal function, which is 1 of the strongest prognostic factors, should also be considered when interpreting the risk-reduction benefit of OPCAB that we have demonstrated in the present study. Our cohort had a lower preoperative median estimated glomerular filtration rate value $\left(41.3 \mathrm{~mL} / \mathrm{min} / 1.73 \mathrm{~m}^{2}\right.$ in ONCAB and $41.6 \mathrm{~mL} / \mathrm{min} / 1.73 \mathrm{~m}^{2}$ in OPCAB) and a higher prevalence of preoperative hemodialysis $(12.7 \%$ in ONCAB and $13.1 \%$ in OPCAB) than those reported for the STS database (median estimated glomerular filtration rate, $71.2 \mathrm{~mL} / \mathrm{min} /$ $1.73 \mathrm{~m}^{2}$ in ONCAB and $69.2 \mathrm{~mL} / \mathrm{min} / 1.73 \mathrm{~m}^{2}$ in OPCAB; prevalence of hemodialysis, $4.5 \%$ in ONCAB and $5.4 \%$ in OPCAB) ${ }^{8}$ Using data from the STS national database, Chawla and colleagues ${ }^{12}$ showed that OPCAB was associated with lower mortality in patients with poor preoperative renal function. The high prevalence of chronic kidney disease in our cohort could explain the strong reduction in mortality in OPCAB despite a smaller sample size than that from the STS database.

OPCAB was also associated with a significantly lower incidence of reoperation for bleeding, perioperative transfusion, mediastinitis, prolonged ventilation, and prolonged ICU stay in this high-risk cohort. Avoidance of transfusion is thought to be among the most important benefits of eliminating extracorporeal circulation. Numerous studies have reported the association of OPCAB with 
reduced requirement for transfusion in patients with a low $\mathrm{EF}^{8,13,14}$; in particular, the well-designed randomized trial of Puskas and colleagues ${ }^{13}$ demonstrated that OPCAB reduced the incidence of coagulopathy. Other recent studies have shown that perioperative blood transfusion was significantly associated with increased mortality after CABG. ${ }^{15,16}$ This evidence suggests that a reduction in transfusion requirement might explain the reduced mortality in our OPCAB cohort.

In the present study, the OPCAB group had a significantly lower incidence of mediastinitis despite the increased use of bilateral internal thoracic arteries in this group. There are several explanations for this reduction of deep sternal wound infection in OPCAB. First, extracorporeal circulation itself can increase the incidence of mediastinitis. In their multivariate analysis of CABG cases from the STS database, Fowler and colleagues ${ }^{17}$ showed that perfusion time longer than 100 minutes was an independent risk factor for major infection. In the present study, both mean perfusion time longer than 150 minutes and perioperative transfusion could explain the increased incidence of mediastinitis in the ONCAB group. Risnes and colleagues ${ }^{18}$ reported that the amount of blood transfused was an independent risk factors for mediastinitis (>10 units; OR, 3.96; 95\% confidence interval, 1.60-9.60). This could be explained by a decrease in immune function after transfusion. ${ }^{19}$

Although many large, retrospective studies have shown that OPCAB may decrease the incidence of stroke compared with ONCAB,${ }^{11,20-23}$ there was no significant difference in the incidence of stroke between OPCAB and ONCAB in the present study. In a large, prospective study of perioperative stroke in CABG, Tarakji and colleagues ${ }^{24}$ reported that intraoperative stroke rates were lowest in OP$\mathrm{CAB}(0.14 \%)$ and on-pump beating-heart CABG $(0 \%)$ and statistically higher with on-pump arrested-heart CABG $(0.50 \%)$. In the present study, about $65 \%$ of the ONCAB cohort underwent the procedure using the on-pump beating-heart technique, which might reduce the incidence of stroke in the ONCAB cohort. In addition, the rates of stroke in our study ( $2.1 \%$ in ONCAB and $1.5 \%$ in OPCAB) are similar to those in the recent study using data from the STS national database $(1.9 \%$ in ONCAB and $1.3 \%$ in $\mathrm{OPCAB}$ ), but the number of patients with OPCAB in the present study is about one-fifth of those in the study using the STS database. ${ }^{8}$ This suggests that the relatively small effect of stroke prevention in our study could not reach significance because of a lack of statistical power. This may partially explain why the previous randomized controlled trials could not show a preventive effect on perioperative stroke, even in high-risk patients. ${ }^{25,26}$

OPCAB patients received slightly but statistically significantly fewer distal anastomoses per patient than
ONCAB patients, which is consistent with results of the CORONARY and ROOBY trials. ${ }^{1,2}$ Furthermore, in the present study, OPCAB patients received bilateral internal thoracic arteries more frequently than ONCAB patients. This might be explained by the effort in the OPCAB cohort to minimize aortic manipulation as much as possible. In fact, aortic no-touch technique was used in about $30 \%$ of the OPCAB cohort in the present study. Siamak and colleagues ${ }^{27}$ reported that the use of bilateral internal thoracic arteries had no significant influence on short-term mortality after CABG in patients with low-EF. Hence, more frequent use of bilateral internal thoracic arteries in OPCAB patients would not significantly affect the short-term outcome in the present study. Because long-term follow-up data were not available in the present study, we could not estimate the prognostic effect of slightly fewer distal anastomoses and more frequent use of bilateral internal thoracic arteries in the OPCAB cohort.

In the present study, 56 patients $(6.1 \%)$ converted from OPCAB to ONCAB. Although this conversion rate was higher than the conversion rate $(2.1 \%)$ in the general population reported from a national survey in Japan, ${ }^{9}$ this was similar to the conversion rate $(5.2 \%)$ for patients with low EF reported from the STS database. ${ }^{8}$ Operative mortality in patients who were converted from OPCAB to ONCAB was very high. Solving the problem of this high mortality with conversion will be necessary to reduce early mortality in OPCAB patients.

The present study has several limitations. First, because of the retrospective nature of this study, propensity-score matching could not completely adjust for potential selection bias. Second, our data on left ventricular function were limited to left ventricular EF, which represents systolic function. No data on left ventricular dimension and diastolic function, which might affect postoperative mortality, were available. Third, because of the lack of long-term data in the present study, our analysis of the clinical benefit of OPCAB technique is limited to short-term outcomes. Finally, we performed the institutional-volume-adjusted analysis but we could not perform the surgeon-volume-adjusted analysis because during 2010 and later (during our study period), the JACVSD served as a part of the NCD and the method of connecting the surgeons and their procedures changed. This change made it impossible to gain data about surgeon volume during the study period. In the previous study from the JACVSD, institutional volume index was significantly associated with 30-day mortality and operative mortality, but on the other hand, the surgeonvolume index was not significantly associated with these outcomes. $^{28}$ Therefore we believe the effect of surgeon volume is more limited than the effect of institution volume. 


\section{CONCLUSIONS}

In patients with an $\mathrm{EF}<0.30$, OPCAB is associated with significantly reduced early mortality and morbidity. Despite the relatively high mortality accompanying unplanned conversion to $\mathrm{ONCAB}$ and the importance of solving this problem, OPCAB technique may improve operative outcomes in this high-risk cohort.

\section{Conflict of Interest Statement}

Authors have nothing to disclose with regard to commercial support.

\section{References}

1. Shroyer AL, Grover FL, Hattler B, Collins JF, McDonald GO, Kozora E, et al. On-pump versus off-pump coronary-artery bypass surgery. $N$ Engl J Med. 2009;361:1827-37

2. Lamy A, Devereaux PJ, Prabhakaran D, Taggart DP, Hu S, Paolasso E, et al. Off-pump or on-pump coronary-artery bypass grafting at 30 days. $N$ Engl $J$ Med. 2012;366:1489-97.

3. Puskas JD, Thourani VH, Kilgo P, Cooper W, Vassiliades T, Vega JD, et al Off-pump coronary artery bypass disproportionately benefits high-risk patients. Ann Thorac Surg. 2009;88:1142-7.

4. LaPar DJ, Bhamidipati CM, Reece TB, Cleveland JC, Kron IL, Ailawadi G. Is off-pump coronary artery bypass grafting superior to conventional bypass in octogenarians? J Thorac Cardiovasc Surg. 2011;141:81-90.

5. Boulton BJ, Kilgo P, Guyton RA, Puskas JD, Lattouf OM, Chen EP, et al. Impact of preoperative renal dysfunction in patients undergoing off-pump versus on-pump coronary artery bypass. Ann Thorac Surg. 2011;92:595-601.

6. Renner A, Zittermann A, Aboud A, Pühler T, Hakim-Meibodi K, Quester W, et al. Coronary revascularization in diabetic patients: off-pump versus on-pump surgery. Ann Thorac Surg. 2013;96:528-34.

7. Ahmed WA, Tully PJ, Baker RA, Knight JL. Survival after isolated coronary artery bypass grafting in patients with severe left ventricular dysfunction. Ann Thorac Surg. 2009;87:1106-12.

8. Keeling WB, Williams ML, Slaughter MS, Zhao Y, Puskas JD. Off-pump and on-pump coronary revascularization in patients with low ejection fraction: a report from the society of thoracic surgeons national database. Ann Thorac Surg. 2013;96:83-8.

9. Masuda M, Kuwano H, Okumura M, Amano J, Arai H, Endo S, et al. Thoracic and cardiovascular surgery in Japan during 2012: annual report by The Japanese Association for Thoracic Surgery. Gen Thorac Cardiovasc Surg. 2014;62:734-64.

10. Jarral OA, Saso S, Athanasiou T. Off-pump coronary artery bypass in patients with left ventricular dysfunction: A meta-analysis. Ann Thorac Surg. 2011;92: 1686-94.

11. Polomsky M, He X, O'Brien SM, Puskas JD. Outcomes of off-pump versus on-pump coronary artery bypass grafting: impact of preoperative risk. J Thorac Cardiovasc Surg. 2013;145:1193-8.

12. Chawla LS, Zhao Y, Lough FC, Schroeder E, Seneff MG, Brenna JM. Off-pump versus on-pump coronary artery bypass grafting outcomes stratified by preoperative renal function. J Am Soc Nephrol. 2012;23:1389-97.

13. Puskas JD, Williams WH, Duke PG, Staples JR, Glas KE, Marshall JJ, et al. Off-pump coronary artery bypass grafting provides complete revascularization with reduced myocardial injury, transfusion requirements, and length of stay: a prospective randomized comparison of two hundred unselected patients undergoing off-pump versus conventional coronary artery bypass grafting. $J$ Thorac Cardiovasc Surg. 2003;125:797-808.
14. Dewey TM, Herbert MA, Prince SL, Magee MJ, Edgerton JR, Trachiotis G, et al. Avoidance of cardiopulmonary bypass improves early survival in multivessel coronary artery bypass patients with poor ventricular function. Heart Surg Forum. 2004; 7:45-50.

15. Paone G, Brewer R, Theurer PF, Bell GF, Cogan CM, Prager RL. Preoperative predicted risk does not fully explain the association between red blood cell transfusion and mortality in coronary artery bypass grafting. J Thorac Cardiovasc Surg. 2012;143:178-85.

16. Bhaskar B, Dulhunty J, Mullany DV, Fraser JF. Impact of blood product transfusion on short and long-term survival after cardiac surgery: more evidence. Ann Thorac Surg. 2012;94:460-7.

17. Fowler VG Jr, O'Brien SM, Muhlbaier LH, Corey GR, Ferguson TB, Peterson ED. Clinical predictors of major infections after cardiac surgery. Circulation. 2005;112:I358-65.

18. Risnes I, Abdelnoor M, Almdahl SM, Svennevig JL. Mediastinitis after coronary artery bypass grafting risk factors and long-term survival. Ann Thorac Surg. 2010;89:1502-9.

19. Murphy PJ, Connery C, Hicks GL Jr, Blumberg N. Homologous blood transfusion as a risk factor for postoperative infection after coronary artery bypass graft operations. J Thorac Cardiovasc Surg. 1992;104:1092-9.

20. Hannan EL, Wu C, Smith CR, Higgins RS, Carlson RE, Culliford AT, et al. Off-pump versus on-pump coronary artery bypass graft surgery: differences in short-term outcomes and in long-term mortality and need for subsequent revascularization. Circulation. 2007;116:1145-52.

21. Sharony R, Grossi EA, Saunders PC, Galloway AC, Applebaum R, Ribakove GH, et al. Propensity case-matched analysis of off-pump coronary artery bypass grafting in patients with atheromatous aortic disease. $J$ Thorac Cardiovasc Surg. 2004;127:406-13.

22. Moss E, Puskas JD, Thourani VH, Kilgo P, Chen EP, Leshnower BG, et al. Avoiding aortic clamping during coronary artery bypass grafting reduces postoperative stroke. J Thorac Cardiovasc Surg. 2015;149:175-80.

23. Al-Ruzzeh S, Ambler G, Asimakopoulos G, Omar RZ, Hasan R, Fabri B, et al. Off-pump coronary artery bypass (OPCAB) surgery reduces risk-stratified morbidity and mortality: a United Kingdom multi-center comparative analysis of early clinical outcome. Circulation. 2003;108(Suppl 1):II1-8.

24. Tarakji KG, Sabik JF III, Bhudia SK, Batizy LH, Blackstone EH. Temporal onset, risk factors, and outcomes associated with stroke after coronary artery bypass grafting. JAMA. 2011;305:381-90.

25. Lemma MG, Coscioni E, Tritto FP, Centofanti P, Fondacone C, Salica A, et al. On-pump versus off-pump coronary artery bypass surgery in high-risk patients: operative results of a prospective randomized trial (on-off study). J Thorac Cardiovasc Surg. 2012;143:625-31.

26. Møller CH, Perko MJ, Lund JT, Andersen LW, Kelbaek H, Madsen JK, et al. No major differences in 30-day outcomes in high-risk patients randomized to off-pump versus on-pump coronary bypass surgery: the best bypass surgery trial. Circulation. 2010;121:498-504.

27. Mohammadi S, Kalavrouziotis D, Cresce G, Dagenais F, Dumont E, Charbonneau E, et al. Bilateral internal thoracic artery use in patients with low ejection fraction: is there any additional long-term benefit? Eur J Cardiothorac Surg. 2014;46:425-31.

28. Miyata H, Motomura N, Ueda Y, Matsuda H, Takamoto S. Effect of procedural volume on outcome of coronary artery bypass graft surgery in Japan: implication toward public reporting and minimal volume standards. J Thorac Cardiovasc Surg. 2008;135:1306-12.

Key Words: off-pump coronary artery bypass grafting, onpump coronary artery bypass grafting, left ventricular dysfunction, propensity score 